\title{
First Two Year Observational Exploratory Real Life Clinical Phenotyping, And Societal Impact Study Of Parkinson's Disease In Emiratis And Expatriot Population Of United Arab Emirates 2019-2021: The Empark Study
}

Vinod Metta ( $\nabla$ docvinodh@doctors.net.uk)

King's College Hospital NHS Foundation Trust

Huzaifa Ibrahim

Parkinson's UAE

Tom Loney

Mohammed Bin Rashid University of Medicine and Health Sciences

Hani Amer

Mohammed Bin Rashid University of Medicine and Health Sciences

Ali Al Hawai Danamir Almuhairi

Higher Colleges of Technology

Abdulla Al Shamsi

Parkinson's UAE

Sneha Mohan

Kings college hospital London Dubai

Kislyn Rodriguez

Kings college hospital London Dubai

Judith Mohan

Kings college hospital London Dubai

Margaret O'Sullivan

Kings college hospital London Dubai

Neha Muralidharan

Kings college hospital London Dubai

Arun Seetha

Kings college hospital London Dubai

Sheikha Al Mazrooei

UAE Stemcell association

Khadeeja DarMousa

POD council of Dubai Police

Guy Chung-Faye

King's College Hospital NHS Foundation Trust

Rukmini Mrudula

Nizam's Institute of Medical Sciences

Cristian Faluo-Pecurariu

Transylvania University of Brașov

Maryam Mattar

UAE Genetics association

Rupam Borgohain 
Nizam's Institute of Medical Sciences

Ray Chaudhuri

King's College Hospital NHS Foundation Trust

\section{Research Article}

Keywords:

Posted Date: February 24th, 2022

DOI: https://doi.org/10.21203/rs.3.rs-1293148/v1

License: (c) (i) This work is licensed under a Creative Commons Attribution 4.0 International License. Read Full License 


\section{Abstract}

Background: phenotypic differences in Parkinson's Disease (PD) among locals (Emiratis) and Expatriots (Expats) living in United Arab Emirates have not been described and could be important to unravel local aspets of clinical heterogenecity of PD pointing towards genetic and epigenetic variations.

Objective: To investigate range and nature of motor and nonmotor clinical presentations of PD and its impact on time to diagnosis, local service provisions, quality of life in Emiratis and Expats in UAE as well as address the presence of current unmet needs on relation to care and aetiopathogenetovty of PD related to possible genetic and epigenetic factors.

Methods: a cross-sectional one point in time prospective, observational real-life study of 171 patients recruited from PD and Neurology clinics across United Arab Emirates from 2019-2021. primary outcomes were sociodemographic data, motor and nonmotor symptoms (NMS) including cognition and sleep, and quality of life (QOL) assessments,

Results: 171 PD patients (52 Emiratis 119 Expats) were included with mean age (Emiratis $48.5+/-13.05$, Expats 64.15+/-7.7) and mean disease duration (Emiratis 4.8+/-3.2, Expats 6.08+/-2.7)

In the e miratis there was a significant mean delay in initiating treatment after diagnosis (Emiratis 1.2+/0.9, Expats 1.6+/1,1 yrs) while from a clinical phenotyping aspect $25 \%$ of Emirati females had a predominant lower limb onset PD. NMS burden was -and fatigue and sexual dysfunction occur independent of disease duration and disease severity in both Emiratis and Expats however, anxiety contributes to $43 \%$ of sexual dysfunction among Emiratis and $41 \%$ among Expats. Emotional well-being and Social Stigma aspects of QoL measurements predicted worse QOL in Emiratis while lack of social support impaired QOL in Expats. Awareness for advanced therapies was low and only 25\% of Emiratis were aware of deep brain surgery compared to $69 \%$ Expats. $2 \%$ of Emiratis compared to $32 \%$ of Expats for Apomorphine infusion and none (0\%) Emiratis were aware of intrajejunal levodopa infusion compared to $13 \%$ of expats.

Conclusion: Our pilot data suggest clinical phenotypic differencesin presentation of PD in Emiratis popuulation of UAE compared to expats. Worryingly the data also shows delayed treatment initiation as well as widespread lack ot knowledge of advanced therapies in the Emirati poopulation.

\section{Background}

Parkinson's disease (PD) is the second most common neurodegenerative disorder, with an increasing prevalence with age, according to a recent study by Vanden Eaden et al. ${ }^{1} 1$ in 10 people aged 45 to 100 are at risk of developing PD and 4 out of every 100 people are diagnosed with PD before the age of 50 (young onset PD) YOPD ${ }^{1}$. Whether or not the frequency of PD varies by race/ethnicity or gender, it is now the leading cause of disability worldwide. Unlike in European and United Kingdom Parkinson's cohorts, Arab families have a high rate of consanguineous marriages ${ }^{2}$ which may increase the risk of genetic phenotypes (YOPD) albeit Familial PD accounts for less than $10 \%$ of all cases of PD $^{3}$. Whilst some studies show low prevalence of PD in some Arab communities especially in Thugba region of Saudi Arabia (27 per 100,000) ${ }^{4}$ in contrast relatively high prevalence in north African $\operatorname{arabs}^{5}$ (31.4-557.4 per 100,000), whereas varied genetically heterogenous patterns were reported in Tunisian study by Gouider -Khouja $\mathrm{N}^{6}$ group.

A pilot study conducted by the Movement Disorders International task force ${ }^{7}$ identified unmet needs in the Middle East, North Africa, South Asia (MENASA) region and recommended requirement and need for multidisciplinary care, increased movement disorders specialists, educational programmes, accurate epidemiologic/genetic data, awareness and availability of more advanced therapies, availability of superior health care resources and infrastructure, and higher levels of awareness to provide care to the people with PD. However, no tangible developments in relation to the aforementioned unmet needs are obvious currently and out study aimed to address the awareness and range and nature of PD in a granular manner in a local UAE population here a comparison with settled expat communities are possible. There are also genetic aspects that has to be considered. For instance The LRRK2, G2019S, autosomal dominant PD with inadequate penetrance and autosomal recessive

Page $3 / 21$ 
inheritance patterns were discovered in a genomic analysis of familial PD in Tunisia ${ }^{8}$ and now known to be prevalent in North African Arabs in Gulf cooperation council countries (GCC) with Arabic population 89 10. This could be due to ancestry disparities between Arabs from the Gulf Cooperation Council and Arabs from North Africa, with the latter being considerably more closely linked to Berber ancestry ${ }^{11}$. As an example, Al-Mubarak et al. ${ }^{11}$ reported no LRRK2 G2019S mutations in the Saudi population they studied.

Furthermore, epidemiologic evidence suggests that ethnicity/racemay play a significant impact on genetic, epigenetic, environmental, cultural, and socioeconomic factors, which may affect the pathophysiology and symptomatic expression in PD 121314 . Given its multi-ethnic population, the United Arab Emirates (UAE), particularly the Dubai area, allows for the study and comparison of endophenotypic variations in carefully selcted locals and expats. The results may aid in the establishment of a biobanking share initiative with the local setup, specifically to study genetic and epigenetic aspects of diseases. Aside from a few anecdotal studies as discussed above no obvious robust prevalence or any endophenotypic studies have been reported or been described among UAE patient cohorts to date. Ours is possibly the first UAE real-life study seeking to understand any specific clinical phenotypic differences in the local Emirati population compared to a wider Expat group in addition to differences in perception of treatment and delivery of care. Methods

Study design

This was a cross-sectional one point in time prospective, observational real-life study of 171 patients recruited from PD and Neurology clinics across United Arab Emirates from 2019-2021. primary outcomes were sociodemographic data, motor and nonmotor symptoms (NMS) including cognition and sleep, and quality of life (QOL) assessments,

This study was carried out in accordance with local ethical committee guidelines. Prior to participating in the study, all patients provided written consent and all data was stored in an anonymised fashion in accordance with the ongoing UK portfolio adopted NILS longitudinal cohort study at the National Parkinson's Centre of Excellence at Kings College Hospital in London, Dubai, in accordance with the General Data Protection Regulation (GDPR UAE). The NILS (UK)study has been authorised by local ethics committees (NRES South-East London REC3, 10,084, 10/H0808/141).

Informed Consent: Informed consent was obtained from patients/carers/all participants involved in this study

\section{Patient Selection}

Patients with a confirmed diagnosis of Parkinson's disease (PD) who met the UK PD Brain Bank criteria were recruited. Referrals to national Parkinson's centre of excellence Kings college hospital Dubai, from all around the UAE (mainly from Dubai, Abu Dhabi Sharjah, A Ain, Ras Al Khaimah, and others) and self-referrals were included.

Separation of Emirati and Expat groups were carried out following established local methodology. Separation of Emirati and Expat groups were carried out following established local methodology. Emirates were UAE nationals and Expats were carefully spected to provide for a comparator group and only included subjects from outside Asia and settled in UAE

\section{Assessments}

During the consultation, as a part of good clinical practice standardised assessment protocols such as Demographics (ethnicity (Emirati vs Expat) age, gender, disease duration) Levodopa Equivalent Daily Dose Calculation (LEDD) ${ }^{15}$. Several motor, Hoehn and Yahr Staging (H\&Y $)^{16}$, and Non-Motor Symptoms Scale (NMSS) ${ }^{17}$, Parkinson's Disease Questionnaire-8 $(\mathrm{PDQ}-8)^{18}$, Kings Parkinson's Pain Scale (KPPS) ${ }^{19}$, PDSS (Parkinson's Disease Sleep Scale) ${ }^{20}$, MMSE (Mini-Mental State Examination) ${ }^{21}$, PFS 16 (Parkinson's Fatigue Scale) ${ }^{22}$, and the Hospital Anxiety Depression Scale (HADS) ${ }^{23}$ were performed. Details of the these validated scales have been published elsewhere and the assessments were performed in line with the NILS assessment; a national study by the National Institute of Health Research in the UK (UKCRN No: 10,084) currently containing data for over 1600 PD patients. 


\section{Statistical Methods}

ANOVA analysis was used to assess differences between two groups (Emiratis and Expats) and the normality of the distribution. Pearson's chi-square correlations analysis was used to investigate whether there were statistical differences in categorical variables between Emiratis and Expats. A p-value of $<0.05$ or a coefficient of determinants $r$ value $>0.4$ was considered statistically significant.

\section{Results}

171 patients of all ages and HY stages of Parkinson's disease from across the UAE (primarily from Dubai, Abu Dhabi Sharjah, Ain, Abu Dhabi, Ras Al Khaima, etc.) were recruited during the period 2019-2021. Patients came from teaching hospitals as well as movement disorders clinics for elderly care, family medicine referrals, and self-referred only patients with PD who met the PD Brain Bank criteria in the United Kingdom were included in this study, along with their primary caregivers, who were also interviewed. Out of 171 overall cohort there were 52 Emiratis and 119 Expats with a mean age of onset of PD of (48.5 \pm 13.05$)$ and $(64.15 \pm 7.7)$ years, respectively., regardless of their origin, similar to other European and Caucasian cohorts. Male preponderance $(73.1 \%)$, compared to females $(26.9 \%)$ is observed in both Emiratis and Expat patients whereas disease duration in Expats cohorts (6.08 \pm 2.7 in years) was longer than Emiratis (4.8 \pm 3.2 in years (Table 1)

Our data also unearthed some differences in care and perception of PD and merits discussion.

Despite the fact there is a reasonable consensus that ${ }^{24}$ that PD treatment should begin at the time of clinical diagnosis ${ }^{24}$, our study suggest that there was a 1.5-year delay in starting PD treatment after formal diagnosis with an average delay of (1.2 \pm 0.9$)$ years in Emiratis and (1.6 \pm 1.1$)$ years in Expats. This may relect local clinical practice and interestingly, we discovered at least three neurologists $(3.5 \pm 1.1)$ were seen by Emiratis compared to expats $(2.5 \pm 0.9)$ consulted before onset of symptoms/diagnosis and initiation of PD treatment. 37\% of Emirati patients were not on any treatment even after 2-5 years of diagnosis even though the UK PDLIFE data clearly suggested worsening in quality of life in patients who are left untreated at diagnosis.

Emiratis appeared to have a higher rate of Young onset Parkinson's disease (PD onset below 50 years) (YOPD) and a mixed sub type of PD (43\%) is followed by Akinetic type with $29 \%$ were seen in both older and younger PD (YOPD) with a lack of tremor dominant phenotype. $25 \%$ of Emirati female patients (25\%) showed Lower Limb tremor dominant subtype compared to their counterparts (Fig 1). Non motor symptoms (NMS) burden (emirates: 54.49, expats: 57.56) especially Sexual dysfunction followed by fatigue was highly prevalent in both male and female Emiratis while Sexual dysfunction, Urinary \& GIT dysfunction is highly prevalent in both male and females Expat patients, as showed and described in previous NMS prevalence studies in non Emirati patients studies ${ }^{25} 2627$. None of the NMS were considered in clinical consultations prior to our assessments and highlighted the under recognition and consequent under treatment of NMS in both Emiratis and Expats as was reported by Chaudhuri et al in a pan European study 17,25

Regardless of the severity of the disease and disease durationfatigue was found to be an independent marker of disease severity by H\&Y staging $(r=0.08, p=0.281)$. Despite the fact that sexual dysfunction is reported by $21 \%$ of all patients in the early stages of Parkinson's disease, it worsened with disease duration and severity $(r=0.42, p<0.01)$ in both Emiratis and Expats. $72 \%$ of Emiratis reported sexual dysfunction whilst on treatment and correlated with high LED $(r=0.72)$ (possibly due to dopamine agonists $\left.{ }^{28}\right)$. Our data suggest a core contribution of anxiety and depression as recorded by $(8.45,7.52)$ to have a significant link with sexual dysfunction especially in both young Emiratis and expats (YOPD) as shown in Table 2.

A difference emerges however, with GIT symptoms, Falls etc. increase with disease duration and have a statistically significant correlation with disease severity $(r=0.51, \mathrm{p} 0.01)$ in both Emiratis and Expats. Unlike Fatigue/Mood/Sexual Dysfunction, falls are strongly linked to disease duration. Fatigue negatively correlates with Sleep scores showing Fatigue and sleep problems are independent Non motor symptoms of PD 2930 (Fig 2). 
Our study showed Quality of life (QOL) (PDQ8 scores) correlate with disease duration and severity implying that quality of life deteriorates with disease duration and disease severity in both Emiratis $(r=0.74)$ and expats $(r=0.64)$ as is widely known. emotional well-being (3.52) and stigma (3.21) were the most affected domains in Emiratis suggesting a strong NMS linked effect whereas social support (2.28) was a dominant issue in Expats. as shown in (Fig 3). This observation may be related to care inequalities in the local health system for Emiratis vs Expats while the prediction of the PD may have a differential effect in the two groups, PD causing more stigma and emotional stress among the Emirates.

PD Emiratis appear are more anxious than depressed, whereas Expats scored equally in both anxiety and depression domains (Fig 4). When we looked at correlations between memory and fatigue domains of NMSS (Non motor symptom scale) and Mini mental state (MMSE) scale and Parkinson's fatigue scale (PFS 16). In both Emiratis $(r=-0.81)$ and Expats $(r=-0.31)$, the NMSS memory domain score is more consistent with MMSE scores. In both Emiratis $(r=0.65)$ and Expats $(r=0.58)$, the NMSS Fatigue score is more consistent with the PFS16 score. Tremor Dominant subtype has the greatest impact on quality of life followed by akinetic dominant PD.

Both Emiratis $(r=-0.06)$ and Expats $(r=-0.05)$ have a total pain score that is not congruent/correlated with disease severity so is the total pain score in both cohorts is unrelated to the disease duration. Nocturnal pain (NP) is more common in all PD Subtypes, whereas radicular pain is more common in the Tremor Dominant Subtype (Fig 5).

A key aspect of our study was the awareness of device aided therapies (DAT) and there were key differences in the groups, $25 \%$ of PD Emiratis, compared to $69 \%$ of Expats aware of deep brain stimulation (DBS). Interestingly only $2 \%$ of Emiratis are aware of Apomorphine infusion treatment, compared with $32 \%$ of Expats. Surprisingly None ( $0 \%$ ) of Emiratis when compared to $13 \%$ of expats, aware of Intrajejunal levodopa infusion (Fig 6). Out of 171 (our study sample) only $8 \%$ were treated with device aided therapies despite the fact that nearly $50 \%$ were eligible.

\section{Discussion}

Our study reports some key findings highlighting differences in PD presentation and care among local PD Emirati population versus a comparator Expat PD group in UAE. These are:

1. The PD Emirati cohort tended to have a larger proportion of Young Onset of Parkinson's (YOPD) compared to Expats

2. Emirati female patients had more frequent Lower limb tremor dominant subtype (25\%) compared to (12.56\%) and LLT group have higher nocturnal, radicular and fluctuation related pain.

3. Emirates PD significantly low age compared to Expat with similar disease severity (HY stage) with a significant lower duration of disease which may be suggestive of a faster disease progression

4. Emirate PD have a significantly low LED inspite of similar HY stage with Expat PD suggesting possible under treatment although dis duration may be a confounder

5. NMS profiles, Qol, are similar across both groups

6. There is a major level of unawareness of advanced therapies across the Emirate PD

We report that the average age of PD Emiratis was significantly lower than the combined expat group. This suggests a higher prevalence of YOPD in this group and as proposed by Khalil et al ${ }^{7}$ (2020) this may underpin a genetic causation or predisposition possibly contributed to by consanguinity in Arab population although this was not specifically studied and is certainly worthy of further larger suitable powered clinical genetic cohort studies. $93.8 \%$ of Emiratis presented to our clinics were YOPD within 1-5 years' duration. It is also considered that the general age of the Emirate population tends to be lower and as such there may be a bias to this observation. 
When data on the Emirate PD is examined in a more granular fashion, then it emerges that the Emirate PD inspite of lower disease duration have similar HY stage compared to the expat group and similar burden of overall NMS scores. A faster disease progression in this group therefore could be proposed on the basis of this observation although lower LED intake in the Emirate group could be a confounder.

The occurrence of higher proportion of LLT in emirate female PD is of interest. LLT has been specifically described to occur in some genetic variants of PD such as in Parkin mutation ${ }^{31}$ as well as in those with LRRK2 ${ }^{32}$ and the data therefore needs more specific observation, genetic and biomarker analysis as well as clinical follow up of this specific cohort. There was a higher representation of nocturnal, fluctuation and radicular pain in the LLT group. This is a preliminary finding and needs to be looked into it in more granular details. Lower back pain as well as shoulder pain (variants of musculoskeletal and radicular pain) have been reported in PINK1 and GBA mutation related PD cases $^{33}$ Fluctuation is often seen at a greater level in YOPD and parkin positive cases. These factors therefore need exploring.

On the whole the overall NMS burden were similar cross both groups and given that the emirate PD group had a significantly lower disease duration this may mean that the clinical PD phenotype in this group may have a greater representation of the recently described NMS endophenotypes ${ }^{34}$. Greater understanding and clarity around this pattern of endophenotype would be important to assign sub type specific treatment and delivery of personalized medicine ${ }^{35}$ in this group.

Finally, we consider vignettes of care delivery of PD across both groups. The Emirates saw more neurologists and inspite of seeing at least 3 neurologists there was a significant delay in initiation of treatment even after diagnosis in UAE PD patients both Emiratis and Expats. Surprisingly 33\% Emiratis were not on any treatment even after 2-5 years of diagnosis and this observation is in conflict with the wider consensus that treatment in PD ought to be started at diagnosis as patients otherwise report progressive deterioration in QoL (Grosset et al ${ }^{24}$ PDLIFE). The issue here may be the provision of care delivery for PD at an early stage.

Delivery of care in PD is also underpinned by successful provision of advanced infusion (apo IJLI) and surgical treatments. Here awareness of patient about these treatments is paramount and our data suggest that only $25 \%$ of Emiratis are aware of the deep brain stimulation surgery (DBS), compared to $69 \%$ of Expats. Interestingly only $2 \%$ of Emiratis are aware of Apomorphine infusion treatment (CSAI), compared with $32 \%$ of Expats. Surprisingly None (0\%) of Emiratis when compared to $13 \%$ of expats, aware of intrajejunal levodopa infusion (IJLI). Out of 171 (our study sample) only $8 \%$ were treated with device aided therapies despite the fact that nearly $50 \%$ were eligible based on delphi 5-2-1 criteria ${ }^{30}$. This may be due to lack of awareness, or specialist skills or experience or advanced device aided therapy (DAT) treatment guidelines to implement these therapies. Some of the Arabic patients and care givers struggled with clinical scales/questionnaires being in English perhaps Arabic translated ones would be beneficial.

The findings consolidate several key unmet needs related to MENASA countries as articulated in the 2020 paper by Khalil et al. ${ }^{7}$ In the Emirate PD well controlled longitudinal cohort studies needs to be undertaken seeking genotype phenotype correlations from a care perspective, awareness for advanced therapies needs to be improved and this needs to be a multilevel educational exercise related to both patients and health care professionals. Such access to therapies can be improved by implementation of a culturally bespoke local clinical guideline for pharmacological as well as non-pharmacological therapies for PD.

Another striking feature of our study we would like to highlight is Emotional Well Being AND Social Stigma predicts QOL in Emiratis, lack of social supports impairs Quality of Life in Expats and anxiety is a predictor of sexual dysfunction especially in Emiratis. Pain in Parkinson's is independent of disease severity so is with disease duration. Nocturnal pain (NP) is found to be higher in all the PD Subtypes whereas Radicular pain dominates Tremor Dominant subtype.

Why early diagnosis and treatment important in PD?

Parkinson's disease is a progressive neurodegenerative condition attributed to progressive loss of dopaminergic neurons emerging evidence supports early intervention may help preserving the functioning of neurons helps in slowing disease

Page $7 / 21$ 
progression and improving overall quality of life $e^{36}$ early treatment depends and relies on early diagnosis, an UK autopsy study of 100 subjects who had been diagnosed with PD found a misdiagnosis rate of $24 \%{ }^{37}$ another study ${ }^{38}$ showed nearly $47 \%$ of PD diagnosis are incorrect when performed in primary care setting and by non-movement disorder specialists. It is necessary that the required skill set and resources to be refined as early detection and treatment have potential to improve the experience and quality of life ${ }^{39}$.

\section{Clinical benefits of early diagnosis and treatment in PD?}

Several studies demonstrated clinical benefit of early treatment. A multicentre controlled clinical trial of Selegilline for 24 months' follow-up on 800 patients in 1987 demonstrated a delayed onset of disability and reduction in motor function (UPDRS) and requirement of Ldopa ${ }^{40}$. Early Parkinson's disease can be managed successfully for up to five years with the use of ropinirole alone and supplementing it with levodopa if necessary. This result is observed in a 5 year follow up study comparing the role of ropinorole vs LDOPA and Bensergide ${ }^{41}$. In another study, Rasagiline treatment demonstrated significant improvement in motor (UPDRS) and no change in onset/frequency of adverse events in a 26-week follow-up study comparing Rasagiline vs Placebo ${ }^{42}$. A 46-month SPECT study of individuals treated with Pramipexole and carbidopa levodopa revealed that the pramipexole-treated group had less dopaminergic neuron degeneration than the carbidopa-treated group, with identical UPDRS scores in both groups ${ }^{43}$. Follow-up for 24 months, in a PET study of patients treated with ropinirole and carbidopa levodopa, the pramipexole-treated group showed decreased dopaminergic neuron degeneration, with equivalent UPDRS ratings in both groups ${ }^{44}$. A 42-week follow-up study of varied multiple doses of carbidopa levodopa revealed a dose-related improvement in motor UPDRS scores ${ }^{45}$. With pramipexole, there was a reduction in dyskinesia and wear-off, but the L-dopa group had a better overall score and motor score, as well as fewer side effects (freezing, somnolence, and edema) ${ }^{46}$. In a metaanalysis of 5247 individuals treated with dopamine agonists and levodopa, patients treated with dopamine agonists had fewer motor problems (dyskinesias, dystonia) than patients treated with levodopa ${ }^{47}$. Individuals treated with MAO B inhibitors had improvements in both motor scores and activities of daily living in a meta-analysis study of 3525 patients treated with MAO B inhibitors and levodopa ${ }^{48}$. Rasagiline $1 \mathrm{mg}$ and $2 \mathrm{mg}$ were compared to placebo in a 72-week follow-up study. With rasagiline 1 $\mathrm{mg}$ but not with $2 \mathrm{mg}$ dosage, the early-start group had better UPDRS scores than the delayed-start group ${ }^{49}$. The 6.5-year extension of the TEMPO research confirmed that the early treated group had less UPDRS score degradation than the delayed onset group ${ }^{50}$. The intervention group experienced a slow onset of dyskinesia and had a higher frequency of dyskinesia ${ }^{51}$. Ldopa improves mobility and gives higher quality of life than dopamine agonists (DA) and monoamine oxidase type B inhibitors, according to a 36-month follow-up study of 1620 patients comparing levodopa and dopamine agonists and MAOB inhibitors ${ }^{52}$ all these studies (randomised clinical trials and meta-analysis) summarised in (table-3) supports treatment should be initiated at the time of diagnosis, delaying the treatment has worst prognostic implications (table 3).

\section{Economical benefits of early diagnosis and treatment in PD?}

Early intervention is likely to have a significant impact on healthcare costs, as well as societal impact several studies showed impact of social healthcare burden and economic costs and quality of life is severe in the later stages of the disease, when symptoms are at their most severe, necessitating more healthcare services or caregiver support ${ }^{39,40,53,54}$. Motor difficulties (motor fluctuations, dyskinesias, and dystonia, which manifests as uncontrollable and sometimes painful muscular spasms) have been recognised as variables contributing to the rise in PD-related expenditures. Social, healthcare burden and economic costs and quality of life in patients with advanced Parkinson's disease (APD) $53,54,55$

Patients with Parkinson's disease (PwP) experience more unpredictable and troublesome motor and non-motor fluctuations as they progress through advanced stages, with the emergence of severe motor (progressive disability) and non-motor symptoms such as mood, cognitive, and behavioural problems, causing a severe impact on QoL and necessitating more healthcare services or caregivers ${ }^{53,54,55}$.

According to a study by Schrag et $\mathrm{al}^{53}$ the overall burden of Parkinson's disease and healthcare resource consumption expenses grew dramatically as the disease progressed with advanced Parkinson's disease (APD). Annual costs for early 
Parkinson's disease were $€ 2,110$, but for advanced Parkinson's disease they were about twenty times higher $(€ 38,625)$, and majority of patients with advanced disease not on any device aided therapies (DAT) elderly over 70 years old ${ }^{53}$. A Spanish study by Zecchinelli et al. ${ }^{56}$ revealed roughly $30 \%$ of Parkinson's patients are in advanced stages, and the cost of illness rose sharply, primarily due to costs linked with in-patient treatment and nursing homes because advanced-stage patients are bedridden, wheelchair-bound, or hospitalised ${ }^{57,58}$. The primary drivers and determinants of the socio-economic burden of PD, were hospitalisation, nursing care, drug costs, indirect costs (loss of work etc.) predictors of quality of life, societal socioeconomic impact healthcare burden and QOL in PwP59,60,61 ( Fig 7)

Study by Popov et al. ${ }^{62}$ looked at costs of PD illness and societal burden in a cohort of 100 patients showed over all annual burden of 1 billion euros with direct costs accounting to $67 \%$ and indirect costs accounting $33 \%$ and main drivers of the burden being informal care and drugs ${ }^{63}$. Another UK study by Mccrone ${ }^{64}$ et al. showed informal care compared to formal ( $80 \%$ vs $20 \%$ impact on societal burden and main predictors being male gender, level of disability and non-motor symptoms like depression ${ }^{64}$. Adherence to oral medications especially in elderly patients with advanced disease where they have to take several pills multiple times strong predictor of socio-economic burden $61 \%$ of PD patients were non-adherent to oral therapy and medical costs were significantly higher among non-adherent versus adherent $(\$ 15,826 \text { vs } \$ 9,228)^{65}$. A multicenter (France, Germany and UK) observational study by Pechevis et al. ${ }^{66}$ showed dyskinesia (motor complications measured using UPDRS scale) was associated with significant socio-economic and societal burden and increasing total healthcare costs with each unit increase in dyskinesia score lead to 562 euros additional costs per patient over a 6 month period ${ }^{66}$.

The economic and clinical evidence gathered in literature shows and confirms that early diagnosis and initiation of treatment is crucial, halts risk of disease progression, reduce the effects on QOL, potential lowering treatment costs if possible non oral therapeutic device aided therapies offered to patients as they progress to advanced stage before significant deterioration has occurred and patients QOL and well-being are improved when Multidisciplinary care approach and timely referrals to movement disorders specialist with expertise in PD as selection of patients for advanced device aided therapies ( IJLI, CSAI,DBS) likely to be most effective and patients likely to be more complaint with these therapies.

\section{Conclusion}

Parkinson's disease in UAE population showed varied heterogenetic, endophenotype variations among Emirati and Expat populations. Non motor symptoms especially Sexual dysfunction, Fatigue, sleep problems etc. are under-rated, under-treated and under diagnosed which needs to be addressed to achieve overall quality of life of patients. Our study narrates the importance of early diagnosis, treatment initiation which has huge societal socio-economic impact and healthcare burden, timely implementation of advanced therapies helps delay PD disease progression. A bio banking share initiative with the local setup specifically to study genetic and epigenetic aspects focussing on: GBA, LRRK2, Parkin gene mutation screening of Emirati patients with young onset Lower limb tremor dependent Parkinson's disease would be beneficial identifying endophenotypes. Setting up local Expert committee panel, implementation of treatment protocols involving patients and career groups (expert patient panel) help empower patients and caregivers.

\section{Declarations}

\section{Competing interests : None declared.}

Authors declare no comepeting financial or Non financial interests

\section{Data Availability statement}

Raw data were generated at Kings College hospital London, Dubai . Derived data supporting the findings of this study are available from the corresponding author VM on request

\section{Contributors}

Page 9/21 
All authors contributed to the designing, drafting and revision of the manuscript for intellectual content, VM \& RC overseen entire writing and editing process

\section{References}

1. Post, B. et al. Young onset Parkinson's disease: A modern and tailored approach. Journal of Parkinson's Disease, 1-8 (2020).

2. Tadmouri, G. O. et al. Consanguinity and reproductive health among Arabs. Reproductive health 6, 1-9 (2009).

3. McInerney-Leo, A., Hadley, D. W., Gwinn-Hardy, K. \& Hardy, J. Genetic testing in Parkinson's disease. Movement disorders: official journal of the Movement Disorder Society 20, 1-10 (2005).

4. Al Rajeh, S. et al. A community survey of neurological disorders in Saudi Arabia: the Thugbah study. Neuroepidemiology 12, 164-178 (1993).

5. Benamer, H. T. \& De Silva, R. LRRK2 G2019S in the North African population: a review. European neurology $63,321-325$ (2010).

6. Gouider-Khouja, N., Belal, S., Hamida, M. B. \& Hentati, F. Clinical and genetic study of familial Parkinson's disease in Tunisia. Neurology 54, 1603-1609 (2000).

7. Khalil, H., Chahine, L., Siddiqui, J., Aldaajani, Z. \& Bajwa, J. A. Parkinson's disease in the MENASA countries. The Lancet Neurology 19, 293-294 (2020).

8. Belarbi, S. et al. LRRK2 G2019S mutation in Parkinson's disease: a neuropsychological and neuropsychiatric study in a large Algerian cohort. Parkinsonism \& related disorders 16, 676-679 (2010).

9. Jasinska-Myga, B. et al. Comprehensive sequencing of the LRRK2 gene in patients with familial Parkinson's disease from North Africa. Movement Disorders 25, 2052-2058 (2010).

10. Alrefai, A. et al. Prevalence of Parkinson's disease in Northern Jordan. Clinical neurology and neurosurgery 111, 812-815 (2009).

11. Al-Mubarak, B. R. et al. Parkinson's disease in Saudi patients: a genetic study. PloS one 10, e0135950 (2015).

12. Hu, M. et al. Parkinsonism in immigrant Afro-Caribbean and Indian subjects living in the United Kingdom. J Neurol Neurosurg Psychiatry 66, 258-259 (1999).

13. Chaudhuri, K. R., Hu, M. \& Brooks, D. Atypical parkinsonism in Afro-Caribbean and Indian origin immigrants to the UK. Movement disorders: official journal of the Movement Disorder Society 15, 18-23 (2000).

14. Dorsey, E. R. \& Bloem, B. R. The Parkinson pandemic-a call to action. JAMA neurology 75, 9-10 (2018).

15. Tomlinson, C. L. et al. Systematic review of levodopa dose equivalency reporting in Parkinson's disease. Movement disorders 25, 2649-2653 (2010).

16. Hoehn, M. M. \& Yahr, M. D. Parkinsonism: onset, progression, and mortality. Neurology 50, 318-318 (1998).

17. Ray Chaudhuri, K. et al. A proposal for a comprehensive grading of Parkinson's disease severity combining motor and nonmotor assessments: meeting an unmet need. PloS one 8, e57221 (2013).

18. Jenkinson, C., Fitzpatrick, R., Peto, V., Greenhall, R. \& Hyman, N. The PDQ-8: development and validation of a short-form Parkinson's disease questionnaire. Psychology and Health 12, 805-814 (1997).

19. Chaudhuri, K. R. et al. King's Parkinson's disease pain scale, the first scale for pain in PD: an international validation. Movement Disorders 30, 1623-1631 (2015).

20. Chaudhuri, K. R. et al. The Parkinson's disease sleep scale: a new instrument for assessing sleep and nocturnal disability in Parkinson's disease. Journal of Neurology, Neurosurgery \& Psychiatry 73, 629-635 (2002).

21. Folstein, M. F., Folstein, S. E. \& McHugh, P. R. “Mini-mental state”: a practical method for grading the cognitive state of patients for the clinician. Journal of psychiatric research 12, 189-198 (1975).

22. Brown, R., Dittner, A., Findley, L. \& Wessely, S. The Parkinson fatigue scale. Parkinsonism \& related disorders 11, 49-55 (2005). 
23. Zigmond, A. S. \& Snaith, R. P. The hospital anxiety and depression scale. Acta psychiatrica scandinavica $67,361-370$ (1983).

24. Grosset, D. et al. A multicentre longitudinal observational study of changes in self reported health status in people with Parkinson's disease left untreated at diagnosis. Journal of Neurology, Neurosurgery \& Psychiatry 78, 465-469 (2007).

25. Chaudhuri, K. R. \& Schapira, A. H. Non-motor symptoms of Parkinson's disease: dopaminergic pathophysiology and treatment. The Lancet Neurology 8, 464-474 (2009).

26. Stacy, M. Nonmotor symptoms in Parkinson's disease. International Journal of Neuroscience 121, 9-17 (2011).

27. Bronner, G. \& Vodušek, D. B. Management of sexual dysfunction in Parkinson's disease. Therapeutic advances in neurological disorders 4, 375-383 (2011).

28. Pavese, N., Metta, V., Bose, S. K., Chaudhuri, K. R. \& Brooks, D. J. Fatigue in Parkinson's disease is linked to striatal and limbic serotonergic dysfunction. Brain 133, 3434-3443 (2010).

29. Pavese, N. et al. [18F] FDOPA uptake in the raphe nuclei complex reflects serotonin transporter availability. A combined [18F] FDOPA and [11C] DASB PET study in Parkinson's disease. Neuroimage 59, 1080-1084 (2012).

30. Antonini, A. et al. Developing consensus among movement disorder specialists on clinical indicators for identification and management of advanced Parkinson's disease: a multi-country Delphi-panel approach. Current medical research and opinion 34, 2063-2073 (2018).

31. Camargos, S. T. et al. Familial Parkinsonism and early onset Parkinson's disease in a Brazilian movement disorders clinic: phenotypic characterization and frequency of SNCA, PRKN, PINK1, and LRRK2 mutations. Movement disorders: official journal of the Movement Disorder Society 24, 662-666 (2009).

32. Clark, L. et al. Frequency of LRRK2 mutations in early-and late-onset Parkinson disease. Neurology 67, 1786-1791 (2006).

33. Criscuolo, C. et al. PINK1 homozygous W437X mutation in a patient with apparent dominant transmission of parkinsonism. Movement disorders: official journal of the Movement Disorder Society 21, 1265-1267 (2006).

34. Sauerbier, A., Qamar, M. A., Rajah, T. \& Chaudhuri, K. R. New concepts in the pathogenesis and presentation of Parkinson's disease. Clinical Medicine 16, 365 (2016).

35. Titova, N. \& Chaudhuri, K. R. Personalized medicine in Parkinson's disease: time to be precise. Movement Disorders 32 , 1147-1154 (2017).

36. Vlaar, A. M., van Kroonenburgh, M. J., Kessels, A. G. \& Weber, W. E. Meta-analysis of the literature on diagnostic accuracy of SPECT in parkinsonian syndromes. BMC neurology 7, 1-13 (2007).

37. Hughes, A. J., Daniel, S. E., Kilford, L. \& Lees, A. J. Accuracy of clinical diagnosis of idiopathic Parkinson's disease: a clinico-pathological study of 100 cases. Journal of neurology, neurosurgery \& psychiatry 55, 181-184 (1992).

38. Conditions, N. C. C. f. C. (Royal College of Physicians).

39. Gage, H., Hendricks, A., Zhang, S. \& Kazis, L. The relative health related quality of life of veterans with Parkinson's disease. Journal of Neurology, Neurosurgery \& Psychiatry 74, 163-169 (2003).

40. Group, P. S. Effects of tocopherol and deprenyl on the progression of disability in early Parkinson's disease. New England Journal of Medicine 328, 176-183 (1993).

41. Rascol, O. et al. A five-year study of the incidence of dyskinesia in patients with early Parkinson's disease who were treated with ropinirole or levodopa. New England Journal of Medicine 342, 1484-1491 (2000).

42. Group, P. S. A controlled trial of rasagiline in early Parkinson disease: the TEMPO Study. Archives of neurology 59, 19371943 (2002).

43. Group, P. S. \& Group, P. S. Dopamine transporter brain imaging to assess the effects of pramipexole vs levodopa on Parkinson disease progression. Jama 287, 1653-1661 (2002).

44. Whone, A. L. et al. Slower progression of Parkinson's disease with ropinirole versus levodopa: the REAL-PET study. Annals of neurology 54, 93-101 (2003).

45. Group, P. S. Levodopa and the progression of Parkinson's disease. New England Journal of Medicine 351, 2498-2508 (2004). 
46. Group, P. S. \& Group, P. S. Pramipexole vs levodopa as initial treatment for Parkinson disease: a randomized controlled trial. Jama 284, 1931-1938 (2000).

47. Stowe, R. et al. Dopamine agonist therapy in early Parkinson's disease. Cochrane Database of Systematic Reviews (2008).

48. Ives, N. J. et al. Monoamine oxidase type B inhibitors in early Parkinson's disease: meta-analysis of 17 randomised trials involving 3525 patients. Bmj 329, 593 (2004).

49. Olanow, C. W. et al. A double-blind, delayed-start trial of rasagiline in Parkinson's disease. New England Journal of Medicine 361, 1268-1278 (2009).

50. Hauser, R. A. et al. Long-term outcome of early versus delayed rasagiline treatment in early Parkinson's disease. Movement Disorders 24, 564-573 (2009).

51. Stocchi, F. et al. Initiating levodopa/carbidopa therapy with and without entacapone in early Parkinson disease: the STRIDE-PD study. Annals of neurology 68, 18-27 (2010).

52. Group, P. M. C. Long-term effectiveness of dopamine agonists and monoamine oxidase B inhibitors compared with levodopa as initial treatment for Parkinson's disease (PD MED): a large, open-label, pragmatic randomised trial. The Lancet 384, 1196-1205 (2014).

53. Schrag, A., Jahanshahi, M. \& Quinn, N. What contributes to quality of life in patients with Parkinson's disease? Journal of Neurology, Neurosurgery \& Psychiatry 69, 308-312 (2000).

54. Kuopio, A. M., Marttila, R. J., Helenius, H., Toivonen, M. \& Rinne, U. K. The quality of life in Parkinson's disease. Movement disorders: official journal of the Movement Disorder Society 15, 216-223 (2000).

55. Duncan, G. W. et al. Health-related quality of life in early Parkinson's disease: The impact of nonmotor symptoms. Movement disorders 29, 195-202 (2014).

56. Zecchinelli, A., Caprari, F., Ponzi, P., Bonetti, A. \& Pezzoli, G. PNL5 SOCIAL COSTS OF PARKINSON DISEASE IN ITALY. Value in Health 6, 788 (2004).

57. Weir, S. et al. Short-and long-term cost and utilization of health care resources in Parkinson's disease in the UK. Movement Disorders 33, 974-981 (2018).

58. Keränen, T. et al. Economic burden and quality of life impairment increase with severity of PD. Parkinsonism \& related disorders 9, 163-168 (2003).

59. Winter, Y. et al. Trends in resource utilization for Parkinson's disease in Germany. Journal of the neurological sciences $\mathbf{2 9 4}$, 18-22 (2010).

60. Richard Dodel J-PR, M. B. a. W. H. O. The Economic Burden of Parkinson's Disease. Report, Touch Briefings (2008).

61. Martinez-Martin, P. et al. Parkinson symptoms and health related quality of life as predictors of costs: a longitudinal observational study with linear mixed model analysis. PLoS One 10, e0145310 (2015).

62. Popova, V. \& Pishtiyski, I. Isolation of cyclodextrin glucanotransferase preparations of different purities. European Food Research and Technology 213, 67-71 (2001).

63. Winter, Y. et al. Social and clinical determinants of quality of life in Parkinson's disease in a Russian cohort study. Parkinsonism \& related disorders 16, 243-248 (2010).

64. McCrone, P., Allcock, L. M. \& Burn, D. J. Predicting the cost of Parkinson's disease. Movement Disorders 22, 804-812 (2007).

65. Davis, K. L., Edin, H. M. \& Allen, J. K. Prevalence and cost of medication nonadherence in Parkinson's disease: evidence from administrative claims data. Movement Disorders 25, 474-480 (2010).

66. Pechevis, M. et al. Effects of dyskinesias in Parkinson's disease on quality of life and health-related costs: a prospective European study. European Journal of Neurology 12, 956-963 (2005).

\section{Tables}

Table 1: Demographics (EMIRATIS Vs EXPATS)

Page 12/21 


\begin{tabular}{|lllll|}
\hline Parameters & Entire Cohort & Emiratis & Expats & p-value \\
\hline Age & $59.29 \pm 14.8$ & $48.5 \pm 13.05$ & $64.15 \pm 7.7$ & $<0.01$ \\
\hline Population wise Disease Duration (years) & $5.7 \pm 3.05$ & $4.8 \pm 3.2$ & $6.08 \pm 2.7$ & $<0.01$ \\
\hline H\&Y & 2.77 & 2.43 & 2.92 & $<0.01$ \\
& & & & \\
\hline LED & 752.11 & 473.08 & 874.03 & $<0.01$ \\
\hline Onset of symptoms & & & & $<0.01$ \\
& 5.70 & 4.85 & 6.08 & \\
\hline Delay in treatment (years) & & & & 0.03 \\
\hline Number of neurologists seen & $1.5 \pm 1.06$ & $1.2 \pm 0.9$ & $1.6 \pm 1.1$ & $<0.01$ \\
\hline
\end{tabular}

Table 2: Standardized assessments 


\begin{tabular}{|c|c|c|c|c|c|c|c|c|c|c|}
\hline \multirow[t]{3}{*}{ NMSS analysis } & \multicolumn{5}{|c|}{ Emiratis } & \multicolumn{5}{|l|}{ Expats } \\
\hline & \multirow{2}{*}{$\begin{array}{l}\text { Male } \\
(\mathrm{N}=30)\end{array}$} & \multirow{2}{*}{$\begin{array}{l}\text { Female } \\
(\mathrm{N}=22)\end{array}$} & \multicolumn{3}{|c|}{ Disease severity } & \multirow[t]{2}{*}{ Male } & \multirow[t]{2}{*}{ Female } & \multicolumn{3}{|c|}{ Disease Severity } \\
\hline & & & $H Y=1.5$ & $\mathrm{HY}=2$ & $H Y=2.5$ & & & $H Y=1.5$ & $H Y=2$ & $\mathrm{HY}=2.5$ \\
\hline NMSS falls & 1.47 & 1.32 & 0 & 0.6 & 1.1 & 2.3 & 2.06 & 0 & 0.5 & 1.4 \\
\hline Fatigue & 5.4 & 4.8 & 4 & 3.5 & 4.9 & 3.5 & 3.4 & 6 & 3.7 & 3.2 \\
\hline Mood/Cognition & 3.6 & 2.6 & 0 & 1.08 & 1.5 & 2.5 & 2.2 & 0 & 0.7 & 1.6 \\
\hline Hallucination & 1.5 & 1.4 & 0 & 0.64 & 1.36 & 2.4 & 2.2 & 0 & 0.8 & 1.5 \\
\hline Memory & 1.7 & 1.5 & 0 & 0.68 & 1.2 & 2.5 & 3.3 & 2 & 0.5 & 1.5 \\
\hline GIT & 3 & 2.1 & 2 & 1.56 & 2.2 & 3.1 & 3 & 2 & 2.1 & 2.3 \\
\hline Urinary & 2.6 & 1.5 & 0 & 0.5 & 3.29 & 3.5 & 2.8 & 0 & 0.4 & 2.5 \\
\hline Sexual Function & 7.9 & 8.2 & 4 & 4.2 & 8.6 & 7.2 & 7.2 & 6 & 4.2 & 5.6 \\
\hline $\begin{array}{l}\text { MIS (Pain or } \\
\text { smell) }\end{array}$ & 2.1 & 1.8 & 1 & 1.2 & 1.7 & 2.3 & 2.1 & 0 & 1.1 & 1.6 \\
\hline PDQ8 & & Em & ratis $(\mathrm{N}=52$ & & & & Exp & ats $(\mathrm{N}=119)$ & & \\
\hline Bodily Discomfort & & 2.3 & & & & & 2.45 & & & \\
\hline Communication & & 1.6 & & & & & 2.12 & & & \\
\hline Cognition & & 1.4 & & & & & 2.25 & & & \\
\hline Social Support & & 1.4 & & & & & 2.28 & & & \\
\hline Stigma & & 3.5 & & & & & 3.33 & & & \\
\hline Emotional WB & & 3.2 & & & & & 3.15 & & & \\
\hline$A D L$ & & 2.0 & & & & & 2.69 & & & \\
\hline PDQ8 Mobility & & 1.7 & & & & & 2.37 & & & \\
\hline HADS Depression & & 7.5 & & & & & 9.92 & & & \\
\hline HADS Anxiety & & 8.4 & & & & & 9.24 & & & \\
\hline \multirow[t]{2}{*}{ KPSS } & & & & \multicolumn{2}{|c|}{ Emiratis } & & & & & \\
\hline & & & & \multicolumn{2}{|c|}{ LL Tre } & \multicolumn{2}{|c|}{ UL Tre } & \multicolumn{2}{|c|}{ Mixed } & Akinet \\
\hline \multicolumn{2}{|l|}{ Radicular Pain } & & & \multicolumn{2}{|c|}{1.5} & \multicolumn{2}{|c|}{1.2} & \multicolumn{2}{|l|}{1.6} & 1.8 \\
\hline \multicolumn{4}{|c|}{ Discoloration/Oedema/Edema } & \multicolumn{2}{|l|}{3} & \multicolumn{2}{|c|}{1.4} & \multicolumn{2}{|l|}{1.6} & 1.6 \\
\hline \multicolumn{4}{|l|}{ Orofacial } & \multicolumn{2}{|c|}{1.2} & \multicolumn{2}{|c|}{3.1} & \multicolumn{2}{|l|}{2.4} & 1.6 \\
\hline \multicolumn{4}{|l|}{ Nocturnal Pain } & 4.5 & & 2 & & 2.5 & & 3.08 \\
\hline Musculoskeletal Pa & & & & 3 & & 1.2 & & 1.7 & & 1.77 \\
\hline Fluctuation Relatec & Pain & & & 3 & & 1.3 & & 1.6 & & 1.46 \\
\hline Chronic Pain & & & & 1.5 & & 1.5 & & 1.7 & & 1.77 \\
\hline & Ent & ire cohort ( & $N=171)$ & Em & iratis $(\mathrm{N}=52$ & & & Expa & ts $(\mathrm{N}=1$ & \\
\hline PFS 16 (Mean) & 10. & & & 11. & & & & 10.24 & & \\
\hline
\end{tabular}


Table 3: Clinical benefits of early diagnosis of Parkinson's disease 


\begin{tabular}{|c|c|c|}
\hline YEAR & STUDY & OUTCOME \\
\hline 1993 & DATATOP & $\begin{array}{l}\text { Selegilline compared with placebo, } 24 \text { months follow up of } 800 \text { patients showed selegeline delayed } \\
\text { the onset of disability and reduction in motor (updrs) and requirement of Ldopa }\end{array}$ \\
\hline \multirow[t]{2}{*}{2000} & & a 5 year follow up study comparing ropinorole vs \\
\hline & $\begin{array}{l}\text { RASCOL } \\
\text { et al }\end{array}$ & $\begin{array}{l}\text { Idopa \& bensergide, patients treated with ropinorole had longer time to dyskinesia's and no } \\
\text { significant difference or change in motor scores or quality of between two groups }\end{array}$ \\
\hline 2002 & TEMPO & $\begin{array}{l}26 \text { weeks follow up study comparing Rasagiline vs Placebo, rasagiline treated group showed } \\
\text { significant improvement in motor (UPDRS) and no difference in onset/frequency of adverse events }\end{array}$ \\
\hline 2002 & $\begin{array}{l}\text { CALM- } \\
\text { PD-CIT }\end{array}$ & $\begin{array}{l}46 \text { months follow up SPECT study of patients treated with Pramipexole and carbidopa levodopa } \\
\text { showed less dopaminergic neuron degeneration in pramipexole treated group with similar UPDRS } \\
\text { scores in both groups }\end{array}$ \\
\hline \multirow[t]{2}{*}{2003} & & $\begin{array}{l}24 \text { months follow up PET study of patients treated with ropinorole and carbidopa levodopa } \\
\text { showed less dopaminergic neuron degeneration in pramipexole treated group with similar UPDRS } \\
\text { scores in both groups }\end{array}$ \\
\hline & $\begin{array}{l}\text { REAL- } \\
\text { PET }\end{array}$ & \\
\hline 2004 & ELLDOPA & $\begin{array}{l}\text { a } 42 \text { weeks follow up study of various multiple doses of carbidopa levodopa showed significant } \\
\text { improvement in motor UPDRS scores in a dose related fashion }\end{array}$ \\
\hline 2008 & $\begin{array}{l}\text { STOOWE } \\
\text { et al }\end{array}$ & $\begin{array}{l}\text { A meta-analysis study } 5247 \text { patients treated with dopamine agonists and levodopa, patients treated } \\
\text { with dopamine agonists has less motor complications (dyskinesia's, dystonia) }\end{array}$ \\
\hline 2008 & & $\begin{array}{l}\text { A meta-analysis study } 3525 \text { patients treated with MAO B inhibitors and levodopa, patients treated } \\
\text { with MAO B inhibitors has improvements in both motor scores and activities of daily living }\end{array}$ \\
\hline & $\begin{array}{l}\text { Ives et } \\
\text { al }\end{array}$ & \\
\hline 2009 & & $\begin{array}{l}72 \text { weeks follow up study comparing Rasagiline } 1 \mathrm{mg} \text { and } 2 \mathrm{mg} \text { compared with placebo showed } \\
\text { Improved UPDRS scores in the early-start group compared to delayed-start group, with rasagiline } 1 \\
\text { mg but not with } 2 \mathrm{mg} \text { dosage }\end{array}$ \\
\hline & ADAGIO & \\
\hline 2009 & $\begin{array}{l}\text { Hauser et } \\
\text { al }\end{array}$ & $\begin{array}{l}6.5 \text { year extension of TEMPO study indeed showed early treated group has less worsening of UPDRS } \\
\text { scores compared to delayed onset }\end{array}$ \\
\hline 2014 & & $\begin{array}{l}36 \text { months follow up study of } 1620 \text { patients comparing levodopa and dopamine agonists and MAOB } \\
\text { inhibitors showed L-dopa improves mobility and provides better quality of life compared to } \\
\text { dopamine agonists (DA) and monoamine oxidase type B inhibitors (MAOBI) }\end{array}$ \\
\hline & $\begin{array}{l}\text { PD MED } \\
\text { TRIAL }\end{array}$ & \\
\hline
\end{tabular}

\section{Figures}




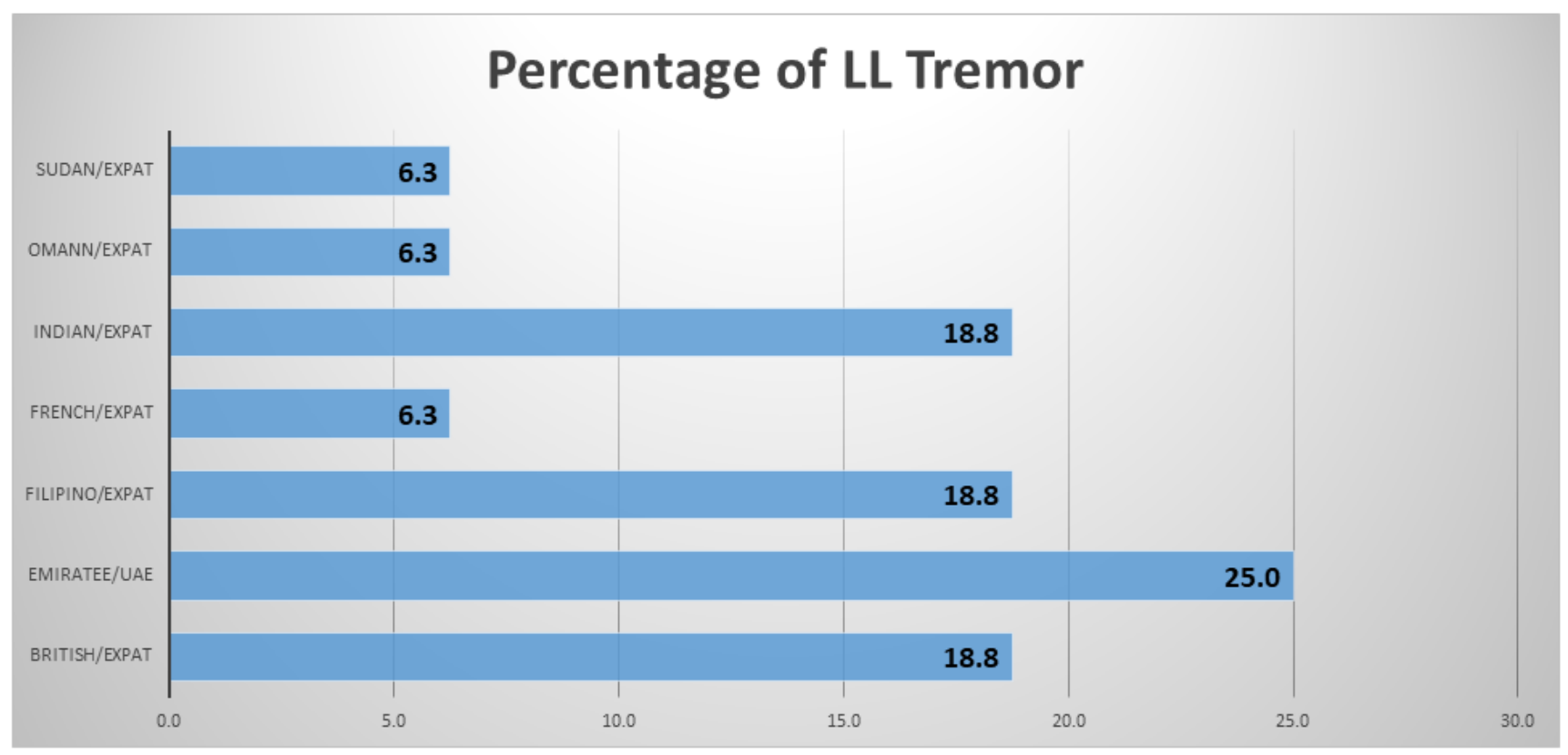

\section{Figure 1}

Graphical representation of the lower limb tremor analysis performed. This graph shows that highest percentage of LL tremor is seen in the Emiratis followed by Indian, Filipino and the British

\section{NMSS VS DISEASE SEVERITY IN EMIRATIS}

$$
\square \mathrm{HY}=1.5 \square \mathrm{HY}=\mathbf{2} \square \mathrm{HY}=2.5
$$

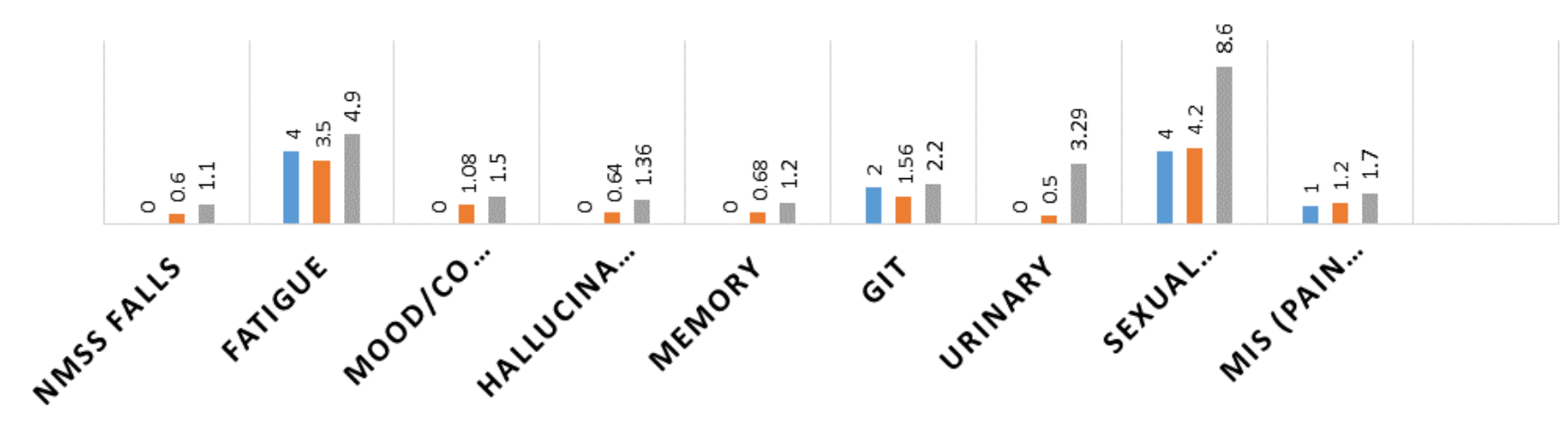

Figure 2

Graphical representation of various non motor symptoms displayed independent disease severity in the Emiratis 


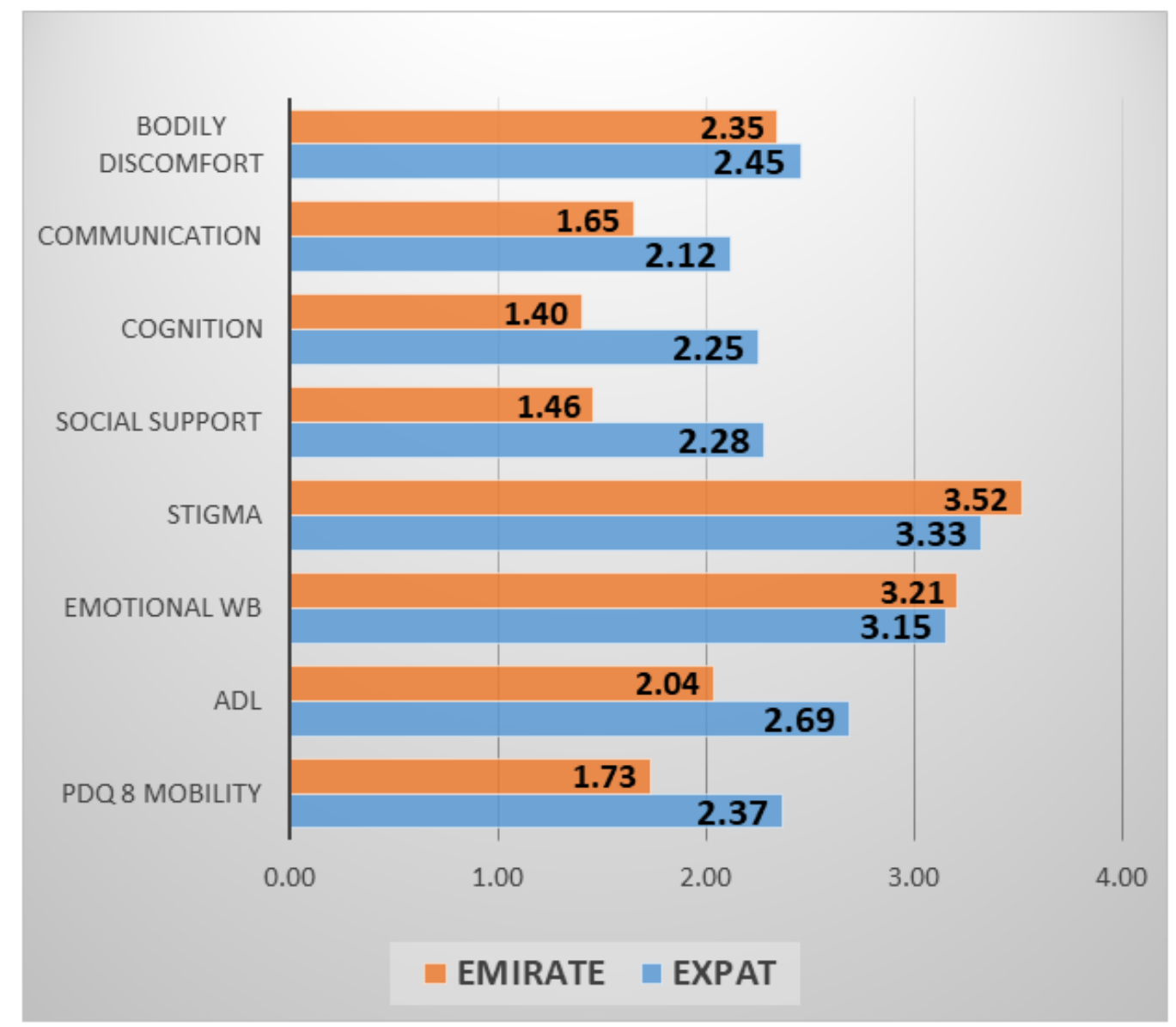

\section{Figure 3}

Graphical representation of various Quality of life domains depicting emotional well being and social stigma directly correlates with the quality of life in Emiratis. On the other hand lack of social support impairs the quality of life among the Expats. 


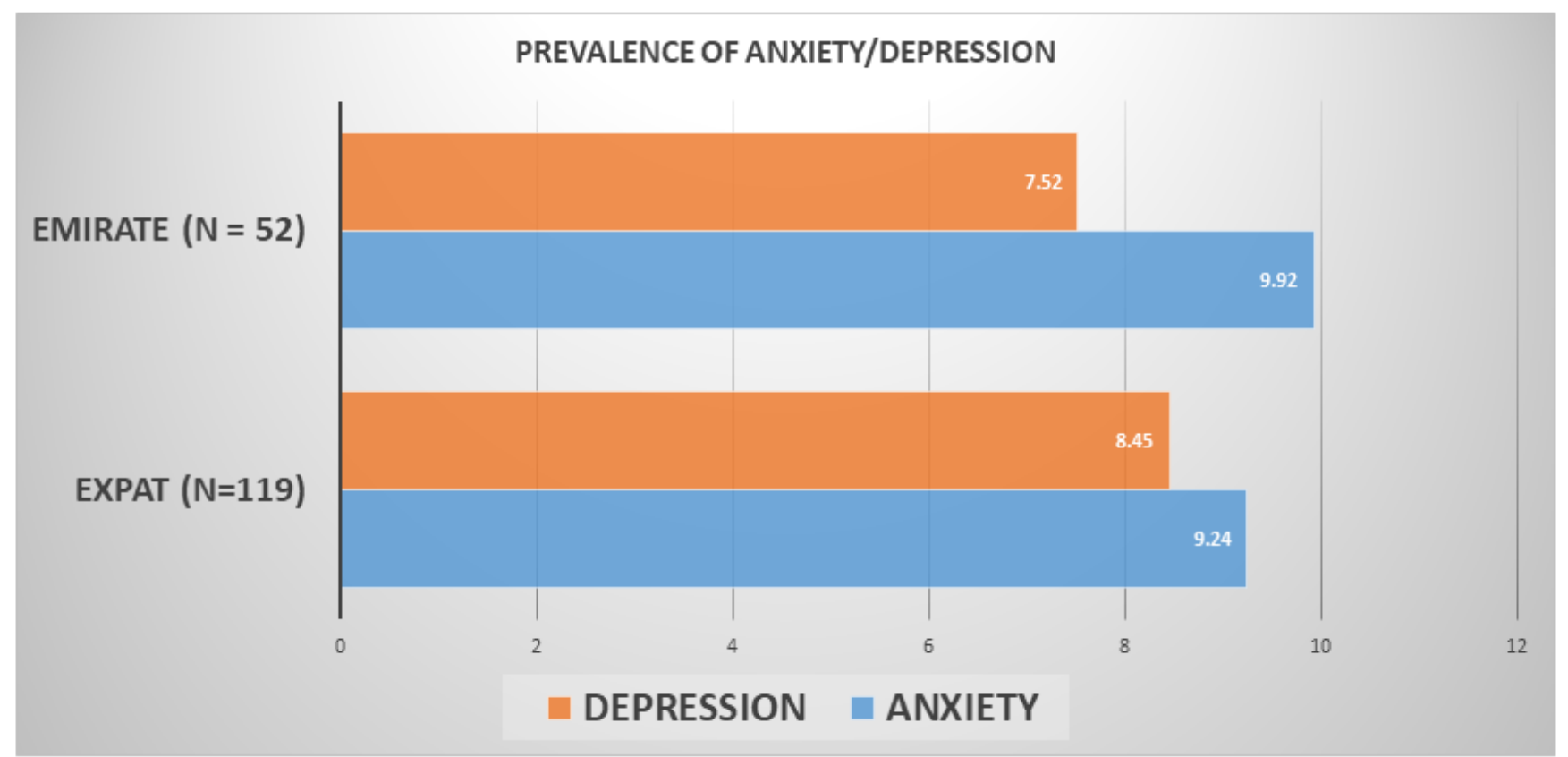

\section{Figure 4}

Graphical representation of prevalence of anxiety and depression in both Emiratis and Expats. Emiratis displayed more anxiety than depression whereas the Expats displayed both equally

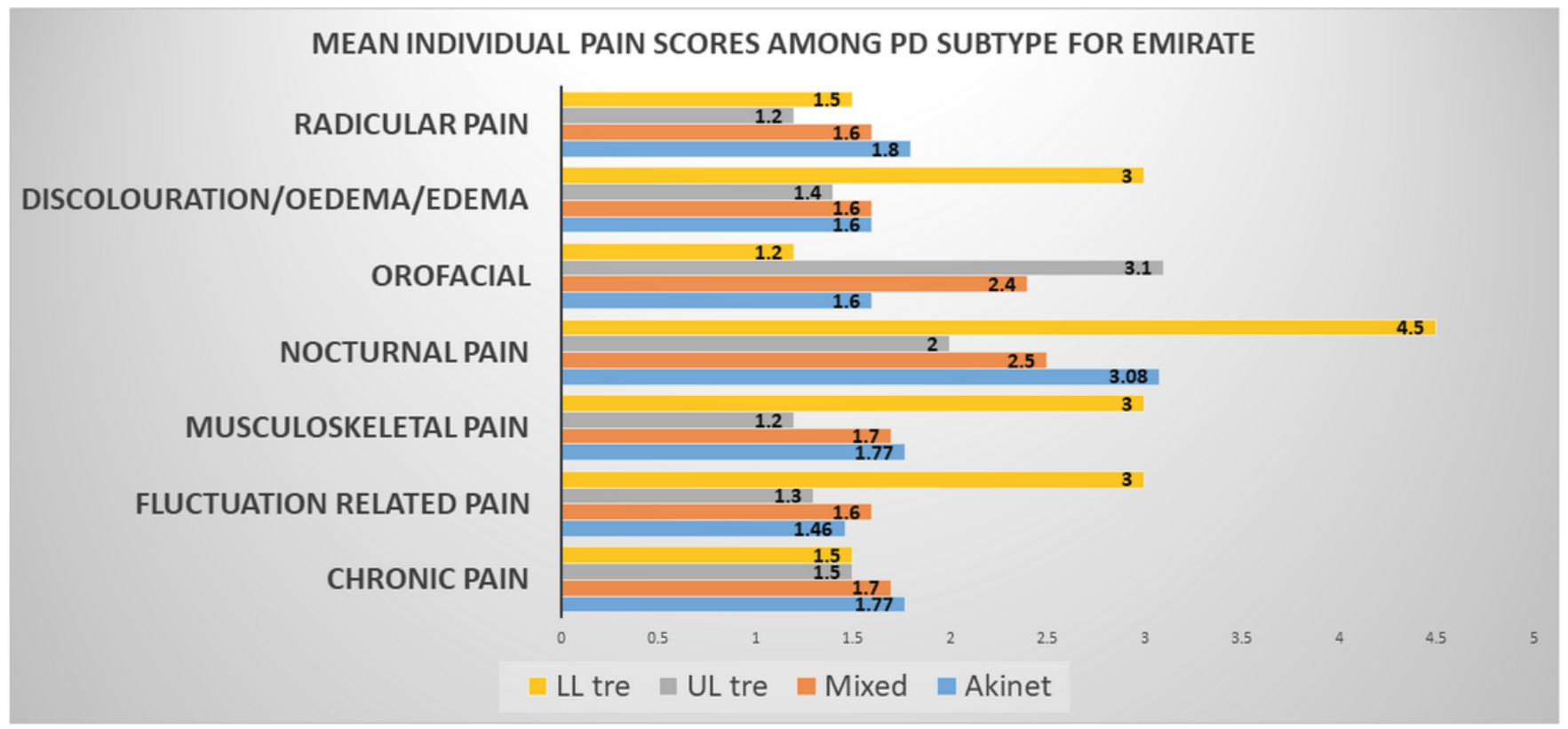

\section{Figure 5}

Graphical representation of PD subtype vs pain domains (KPPS) in Emiratis. In this graph it can be seen that Nocturnal pain (NP) is found to be higher in all the PD Subtypes where as Radicular pain scores high in Tremor Dominant Subtype 


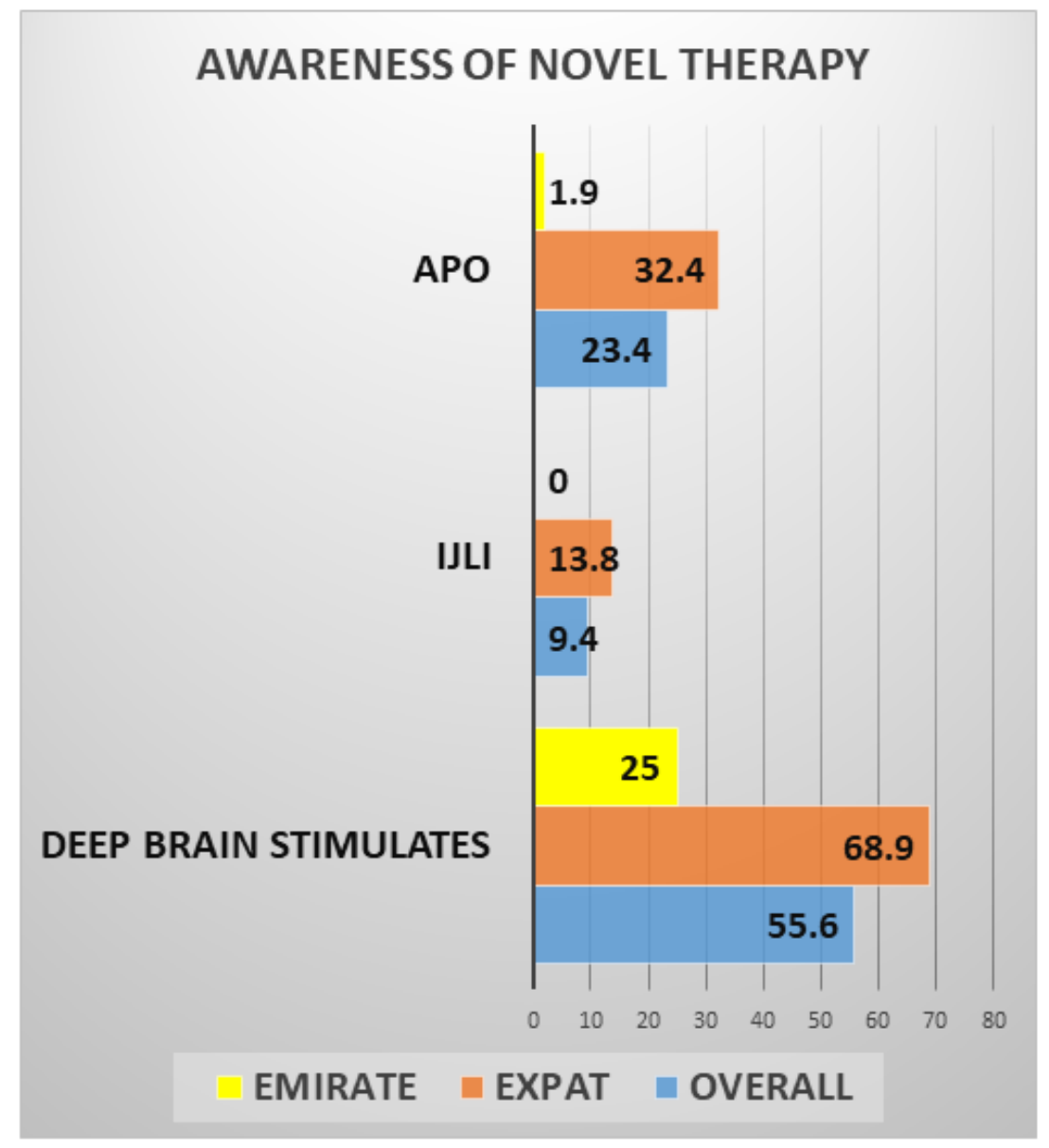

\section{Figure 6}

Graphical representation of the awareness of novel therapies in PD treatment among the Emiratis and Expats. This graph shows only $25 \%$ of Emirates are aware of deep brain stimulation test compared to $69 \%$ Expats and $2 \%$ of Emirates are aware of Apomorphine pump treatment compared to $32 \%$ of Expats. Whereas Not even a single ( $0 \%)$ Emirati is aware of lleo-jejunal levodopa infusion compared to $13 \%$ of expats. 


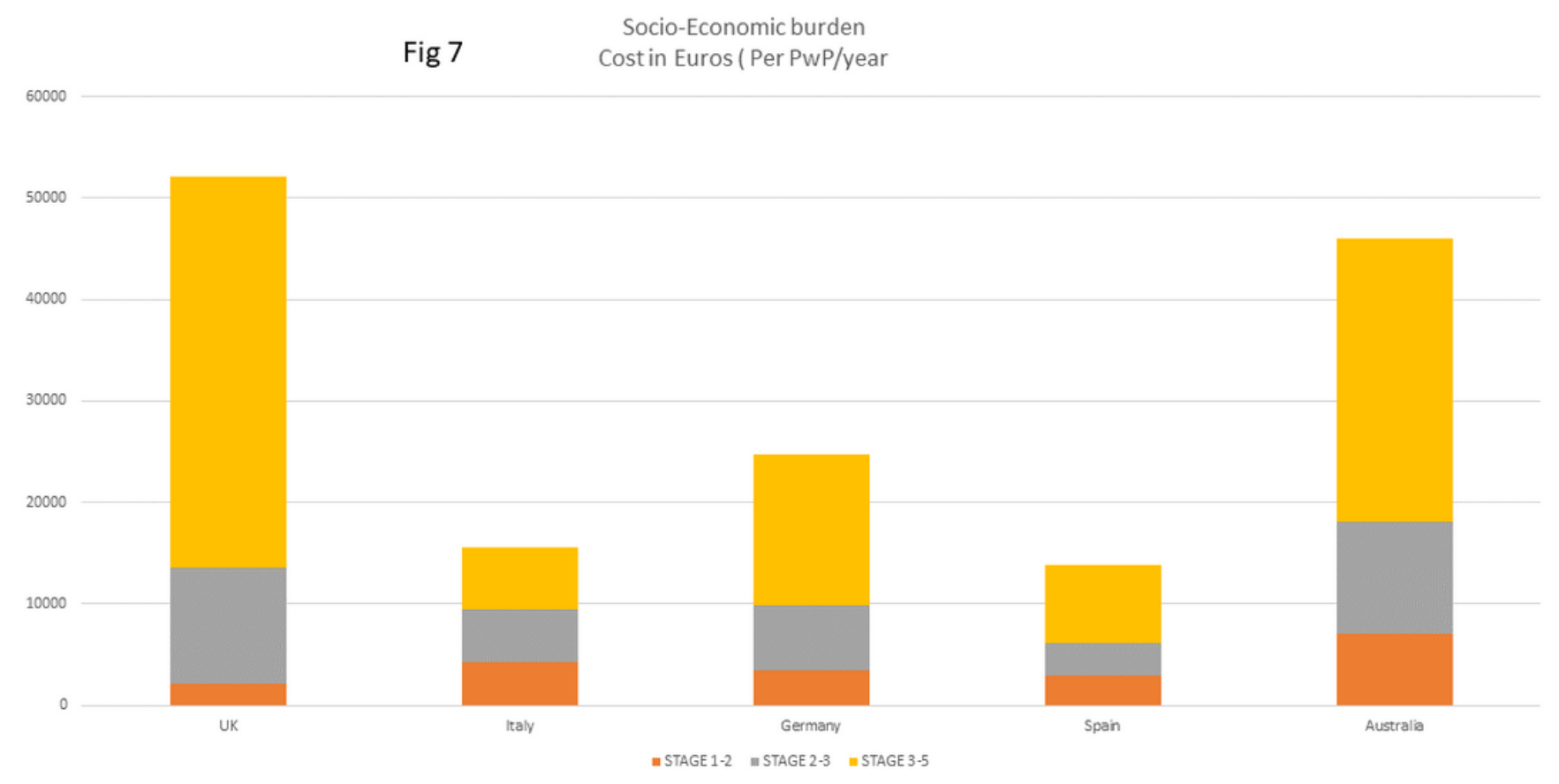

\section{Figure 7}

highlighting socio-economic burden increases as disease progress (yellow) 